\title{
Genome editing: 7 facts about a revolutionary technology
}

What everyone should know about cut-and-paste genetics.

Lucy Odling-Smee, Heidi Ledford \& Sara Reardon

30 November 2015

The ethics of human-genome editing is in the spotlight again as a large international meeting on the topic is poised to kick off in Washington DC. Ahead of the summit, which is being jointly organized by the US National Academy of Sciences, the US National Academy of Medicine, the Chinese Academy of Sciences and Britain's Royal Society and held on 1-3 December, we bring you seven key genome-editing facts.

\section{Just one published study describes genome editing of human germ cells.}

In April, a group led by Junjiu Huang at Sun Yat-sen University in Guangzhou, China, described their use of the popular CRISPR-Cas9 technology to edit the genomes of human embryos. Only weeks before the researchers' paper appeared in Protein \& Cell ${ }^{1}$, rumours about the work had prompted fresh debate over the ethics of tinkering with the genomes of human eggs, sperm or embryos, known collectively as germ cells. Huang and colleagues used non-viable embryos, which could not result in a live birth. But in principle, edits to germ cells could be passed to future generations.

2. The law on editing human germ cells varies wildly across the world.

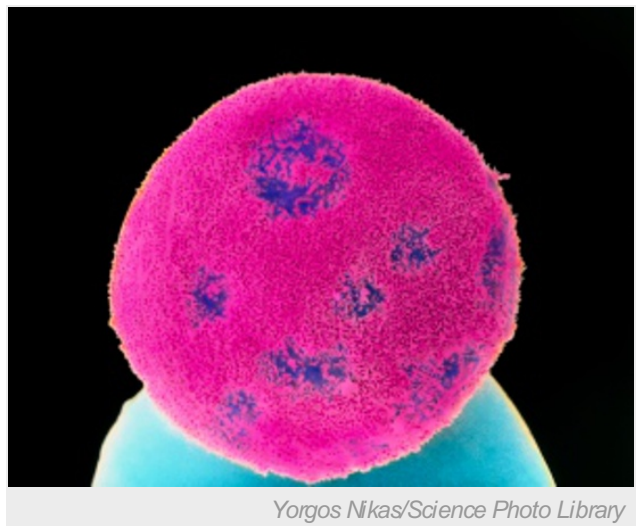

Human embryos are at the centre of a debate over the ethics of genome editing.

Germany strictly limits experimentation on human embryos, and violations can be a criminal offence. By contrast, in China, Japan, Ireland and India, only unenforceable guidelines restrict genome editing in human embryos. Many researchers long for international guidelines, and some hope that the upcoming summit in Washington DC could be the start of the process to create them.

\section{You don't have to be a pro to hack genomes.}

The CRISPR-Cas9 technology has made modifying DNA so cheap and easy that amateur biologists working in converted garages or community laboratories are starting to dabble.

\section{Cas9 is not the only enzyme in town.}

A key ingredient in the CRISPR-Cas9 system is the DNA-cutting enzyme Cas9. But in September, synthetic biologist Feng Zhang at the Broad Institute of MIT and Harvard in Cambridge, Massachusetts, reported the discovery of a protein called Cpf1, which may make it even easier to edit genomes ${ }^{2}$. (Zhang is one of those who pioneered the use of CRISPR-Cas9 for genome editing in mammalian cells).

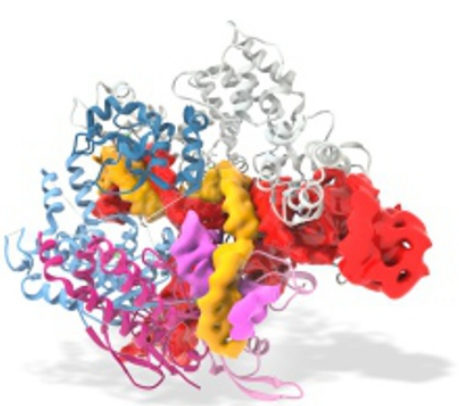

Ramon Andrade 3Dciencia

The CRISPR-Cas9 system makes editing 


\section{Pigs are on the front line of genome-editing experiments.}

Dogs, goats and monkeys are all part of the growing CRISPR zoo. But pigs in particular have been at the heart of several eye-catching announcements from micropigs that weigh about six times less than many farm pigs, to supermuscly pigs, to a pig whose genome has been edited in 62 places (the aim being to produce a suitable non-human organ

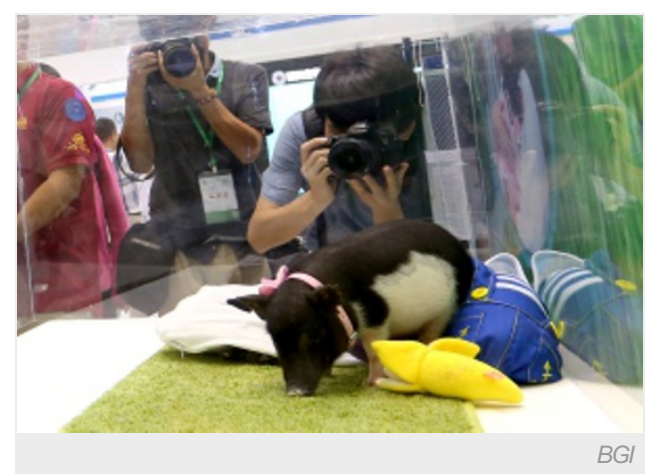

A gene-edited micropig created by the BGI in Shenzen, China. donor).

\section{Gates, Google and DuPont want a piece of the genome-editing action.}

In August, several high-profile investors, including the Bill \& Melinda Gates Foundation and Google Ventures, pumped US\$120 million into the genome-editing firm Editas Medicine of Cambridge, Massachusetts. Big Agriculture is following suit: DuPont forged an alliance with the genome-editing firm Caribou Biosciences of Berkeley, California, in October, and announced its intention to use CRISPR-Cas9 technology to engineer crops.

\section{The CRISPR-Cas9 system is at the centre of a patent row.}

Zhang was granted a US patent on CRISPR-Cas9 in April 2014. But several months before he filed his application in 2012, molecular biologists Jennifer Doudna at the University of California (UC), Berkeley, and Emmanuelle Charpentier, now at the Max Planck Institute for Infection Biology in Berlin, had filed their own patent. UC Berkeley has since requested that the United States Patent and Trademark Office determine who should get credit for harnessing the CRISPR-Cas9 system, in particular for its application in human cells. And a similar debate is playing out in Europe, where oppositions to a patent that Zhang and his colleagues won in February have been filed. All three scientists co-founded companies that make use of CRISPR-Cas9.

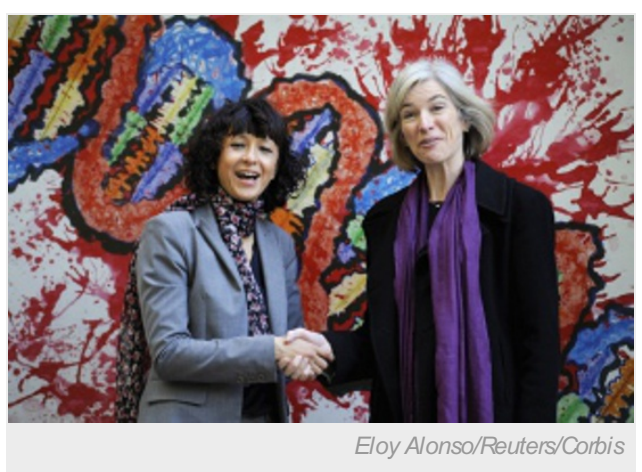

Microbiologists Emmanuelle Charpentier and Jennifer Doudna.

Nature I doi:10.1038/nature.2015.18869

Nature ISSN0028-0836 日SSN 1476-4687

\section{SPRINGER NATURE}

